\title{
TİROTOKSİKOZUN NADİR BİR NEDENİ: MOL HİDATİFORM
}

\author{
A Rare Cause of Thyrotoxicosis: Hydatidiform Mole
}

\section{Zafer PEKKOLAY ${ }^{1}$, Fatih Mehmet FINDIK² ${ }^{\mathbf{2}}$ Hikmet SOYLU ${ }^{1}$, Belma Özlem TURAL BALSAK ${ }^{1}$, Alpaslan Kemal TUZCU ${ }^{1}$}

\author{
${ }^{I}$ Dicle Üniversitesi Tip Fakültesi, İ̧̧ Hastalıkları Anabilim Dalı, Endokrinoloji Bilim Dall, DIYARBAKIR \\ ${ }^{2}$ Dicle Üniversitesi Tıp Fakültesi, Kadın Doğum Hastalıkları Anabilim Dalı, DiYARBAKIR
}

\begin{abstract}
Gestasyonel premalign trofoblastik hastalık olan mol hidatiform, doğurganlık çağındaki kadınlarda hipertroidinin nadir bir nedeni olarak karşımıza çıkmaktadır. Trofoblastlarca salınan koriyonik gonadotropinin alfa alt ünitesi, tiroid stimule edici hormona benzediğinden tiroid bezini uyararak hipertroidi oluşturabilir. Mol hidatiformun primer tedavisi cerrahidir. Olgu sunumumuzda yirmibeş yaşında mol hidatiforma bağlı belirgin hipertroidisi olan kadın hasta sunuldu. Hasta kombine antitiroid ilaçlarla operasyona hazır hale getirildi ve başarılı bir şekilde opere edildi. Operasyon sonrası takibinde, klinik ve laboratuvar bulguları normale döndü.
\end{abstract}

Anahtar Kelimeler: Antitiroid ilaçlar, mol hidatiform, tirotoksikoz
Mole hydatidiform, a gestational premalign trophoblastic disorder, is a rare cause of hyperthyroidism in women of childbearing age. Since the chorionic gonadotropin released by the trophoblasts is similar to the alpha subunit thyroid stimulating hormone, it stimulates the thyroid gland to form hyperthyroidism. Obvious hyperthyroidism in gestational trophoblastic disease is very rare. Primary therapy of hydatidiform is surgery. A 25-year-old woman has hyperthyroidism due to hydatidiform mole. The patient was made ready for operation with combined antithyroid drugs and was successfully treated. Clinical and laboratory findings were normalized postoperatively.

Keywords: Antithyroid drugs, hydatidiform mole, thyrotoxicosis 


\section{GíRiș}

Mol hidatiform plasentadan köken alan uterusa invazyon gösterebilen premalign gestasyonel trofoblastik bir hastalıktır (1). Trofoblastlar tarafindan üretilen insan koriyonik gonadotropin (hCG)'in alfa $(\alpha)$ alt ünitesi tiroid stimule edici hormon (TSH), lüteinizan hormon $(\mathrm{LH})$, folikül stimule edci hormon (FSH) ile aynıken beta alt ünitesi farklıdır. Glikoprotein yapısındaki $\alpha$ alt ünitesi TSH reseptörüne bağlanır ve onu aktive eder. Yüksek konsantrasyondaki hCG, tiroid bezini uyararak diffüz guatr, serbest T3 ve serbest T4 artışı yapar. TSH baskılanır ve belirgin hipertroidizm gelişir (2). Molar gebelik, gebeliğin nadir komplikasyonlarından biridir. Yüzde beş hastada klinik hipertiroidizm gelişir, nadiren ciddi tirotoksikoz yapar (3). Molar gebeliğin tedavisi dilatasyon, küretaj gerekirse histerektomidir. Operasyon sonrası dönemde hastalık remisyona girmezse veya invaziv hastalık varsa kemoterapi verilir (4).

$\mathrm{Bu}$ olgu sunumunda, molar gebeliğe bağlı ciddi tirotoksikozu olan hastanın operasyon öncesi hazırlığı sırasında edindiğimiz tecrübeyi paylaşmak istedik.

\section{OLGU}

Yirmibeş yaşında kadın hasta altıncı gebeliğinin 13 . haftasında vajinal kanama nedeniyle Kadın Hastalıkları ve Doğum polikliniğine başvurdu. Özgeçmişinde tiroid patolojisi ve mol gebelik öyküsü yoktu. Ultrasonografide endometrial kavitede kistik alanlar ve mol hidatiform ile uyumlu bulgular saptanması üzerine operasyon planlanarak hastaneye yatırıld1. Anestezi indüksiyonu aşamasında, belirgin taşikardi gelişen hasta opere edilemedi ve yeniden değerlendirmeye alındı. Hastada hafif şiddette Hiperemezis gravidarum semptomları ve taşikardi tespit edildi; bunun dişında izlenen hipertiroidi semptomu yoktu. Kan basınc1 100/60 mmHg, Nabı: 102 vuru/dk idi. Fizik muayenede gebelik, tiroid muayenesinde hafif diffüz guatr (Grade 1) ve taşikardi tespit edildi; bunun dişında bir bulgu saptanmadı. Tiroid fonksiyon testlerinde belirgin hipertiroidi saptanması üzerine, kliniğimize preoperatif hazırlık için danışıldı. Hastanın tiroid otoantikorları negatif saptand1. Mol hidatiforma bağl1 tirotoksikoz düşünüldü. EKG'sinde sinüs taşikardisi mevcuttu. Tiroid USG'sinde diffüz guatr ve kanlanma artışı gözlendi. Hemoglobin 12 gr/dl idi. Hastaya Metimazol (40 mg/gün), lityum (600 mg/gün), metilprednisolon (40 $\mathrm{mg} /$ gün), propranolol (80 mg/gün), lugol solüsyonu (15 damla/gün), kolestiramin ( $8 \mathrm{~g} /$ gün) verilerek, bir hafta sonunda operasyona hazır hale getirildi. Hasta 1lımlı hipertiroidi değerlerine getirilerek, spinal anestezi ile operasyona alındı. Operasyon sirasında ve sonrasında bir komplikasyon gelişmedi. Postoperatif dönemde lityum, metimazol, metilprednisolon tedavisi kesildi; kolestiramin ve propranolole devam edildi. Takip döneminde tiroid fonksiyon testleri ve hCG değerleri geriledi. Hipertiroidi semptomları kaybolan hastanın son iki ilacı da kesildi. Laboratuvar değerleri normal değerlere yaklaştı (Tablo 1).

Tablo 1: Hastanın laboratuvar sonuçları

\begin{tabular}{lcccc}
\hline Laboratuvar değerleri & Tanı anında & Operasyon öncesi & Operasyon sonras1 & Kontrol \\
\hline TSH (0.27-4.2) $\mu 1 \mathrm{u} / \mathrm{ml}$ & 0.01 & 0.01 & 0.01 & 0.17 \\
Serbest T3 (3.1-6.8) ng/dl & 28.15 & 10 & 5 & 4.51 \\
Serbest T4 (12-22) pmol/L & 100 & 53 & 44 & 12.42 \\
Beta hCG miu/ml & 833225 & $>1000000$ & 204905 & 877 \\
\hline
\end{tabular}




\section{TARTIŞMA}

Tirotoksikoz tüm gebeliklerin en fazla \%1'inde görülür. En sık nedeni Graves hastalığıdır. Hastamızda tiroid otoantikorları negatif saptandı ve graves hastalığının göz bulguları yoktu. Doğurganlık çağındaki kadınlarda mol hidatiforma bağlı tirotoksikoz çok nadir bir durumdur (5). Mol hidatiforma bağlı tirotoksikoz tablosuna hiperemezis eşlik edebilir (6). Bizim hastamızda hiperemezis mevcuttu. Mol hidatiformun primer tedavisi cerrahidir. Tirotoksikoza bağlı kardiyak etkiler ve tiroid krizi riski morbidite ve mortalite açısından önemlidir. Mol hidatiform ilerleyici, invaziv bir hastalık olduğundan cerrahi tedavinin geciktirilmemesi gerekmektedir. Geç kalındığında koryokarsinoma dönüşebilir. Hızlı ötiroidiyi sağlamak için thionamidler, lugol solüsyonu, lityum, kolestiramin, propranolol, radyokontrast ajanlar, glukokortikoidler kullanılmakta ve gerektiğinde plazmaferez yapılmaktadır (7-9). Hastamıza hipertiroidiyi hızlı düzeltmek amacıyla metimazol tercih edildi. Molar gebelikte uterus boşaltıldıktan sonra, zaman içinde hCG normal seviyelere gelmekte ve tirotoksik durum düzelmektedir (10).

Sonuç olarak doğurganlık çağındaki kadınlarda mol hidatiform saptandığında, tiroid fonksiyonlarına bakılmalıdır. Belirgin hipertiroidili hastalar, antitiroid ilaç kombinasyonlarıyla hızlı bir şekilde operasyona hazır hale getirilebilir.

\section{KAYNAKLAR}

1. Berkowitz RS, Goldstein DP. Current advances in the management of gestational trophoblastic disease. Gynecol Oncol. 2013; 128(1): 3-5.

2. Davies TF, Laurberg P, Bahn RS. Hyperthyroid Disorders. Williams Textbook of Endocrinology. 13th ed. Philadelphia, PA: Elsevier. 2016. Chapter 12: $369-415$.
3. Kurdi MS. Hydatidiform mole: A sour encounter with a grapy case. Indian J Anaesth. 2011; 55: 1713.

4. Jelly P, Rakesh S. Gestational trophoblastic disease (GTD). International Journal of Medical Paediatrics and Oncology. 2016; 2(2): 70-3.

5. Carney LA, Quinlan JD, West JM. Thyroid disease in pregnancy. Am Fam Physician. 2014; 89(4): 273-8.

6. Braverman L, Utiger R. Introduction to thyrotoxicosis. In: Braverman L, Utiger R eds. The Thyroid. 9th ed. Philadelphia: Lippincott Williams \& Wilkins. 2005: 453-5.

7. Aggarwal R, Pradeep C. Management of hyperthyroidism in pregnancy. International Journal of Reproduction, Contraception, Obstetrics and Gynecology. 2016; (5)1: 1-5.

8. Noal S, Joly F, Leblanc E. Management of gestational trophoblastic disease. Gynecol Obstet Fertil. 2010; 38: 193-8.

9. Narasimhan KL, Ghobrial MW, Ruby EB. Hyperthyroidism in the setting of gestational trophoblastic disease. Am J Med Sci. 2002; 323: 285-7.

10. Chiniwala NU, Woolf PD, Bruno CP, Kaur $\mathrm{S}$, Spector H, Yacono K. Thyroid storm caused by a partial hydatidiform mole. Thyroid. 2008; 18(4): 479-81. 